\title{
Words are not wasted when there is soup to deliver
}

$\mathrm{S}$ pring came reluctantly to Yellowknife in the Northwest Territories this year, but finally the ice bridge over the Mackenzie River gave way to a ferry crossing, just in time for my new grand piano to travel by road from Kelowna, British Columbia. I arrived home from work to find my friend and trusted piano dealer in my living room. After spending 3 days on the road with the piano, his next challenge was to wrestle the piano into our inaccessible living room.

Then the cell phone rang. I wasn't of on call, but I smiled when I heard a familiar voice: "Hello, it's Anna from Home Care. I'm so sorry to bother you, but I can't reach the physicians who have been following one of our palliative patients."

The family physician was in an out- lying community and the locum could not be reached by phone. The palliative care call "group" in Yellowknife consists of myself, anytime, as long as I can be reached, precisely because of situations like these.

The patient, a young father of 3, was dying at home of a malignancy. He had just been started on some morphine for respiratory distress, but Anna felt he would benefit from a benzodiazepine as well. I couldn't give her a phone order for a patient I'd never seen, so we arranged for a home visit the next day - my day off, but I would welcome another commitment around the time that my piano would be dangling from a crane in the front yard.

Next came the delicate task of soliciting a consult. I cannot advertise myself as a palliative care specialist, but most family physicians accept my involvement through Home Care during their own absences, or in the event that a homebound patient requires internal medicine services. Yellowknife's home care nurses are the local experts in symptom management and they can usually wrangle a consult when needed. In this case, the family physician was happy to oblige.

Arriving at the little house the next day, I found the door open and walked in to find Karen, another nurse, at the kitchen table. The patient's young wife, wearing pyjamas and a bandana, had more dignity and grace about her than many a suit-clad business type.

She handed me a plate of waffles, pointed to the syrup, and continued her discussion of which medications were really needed.

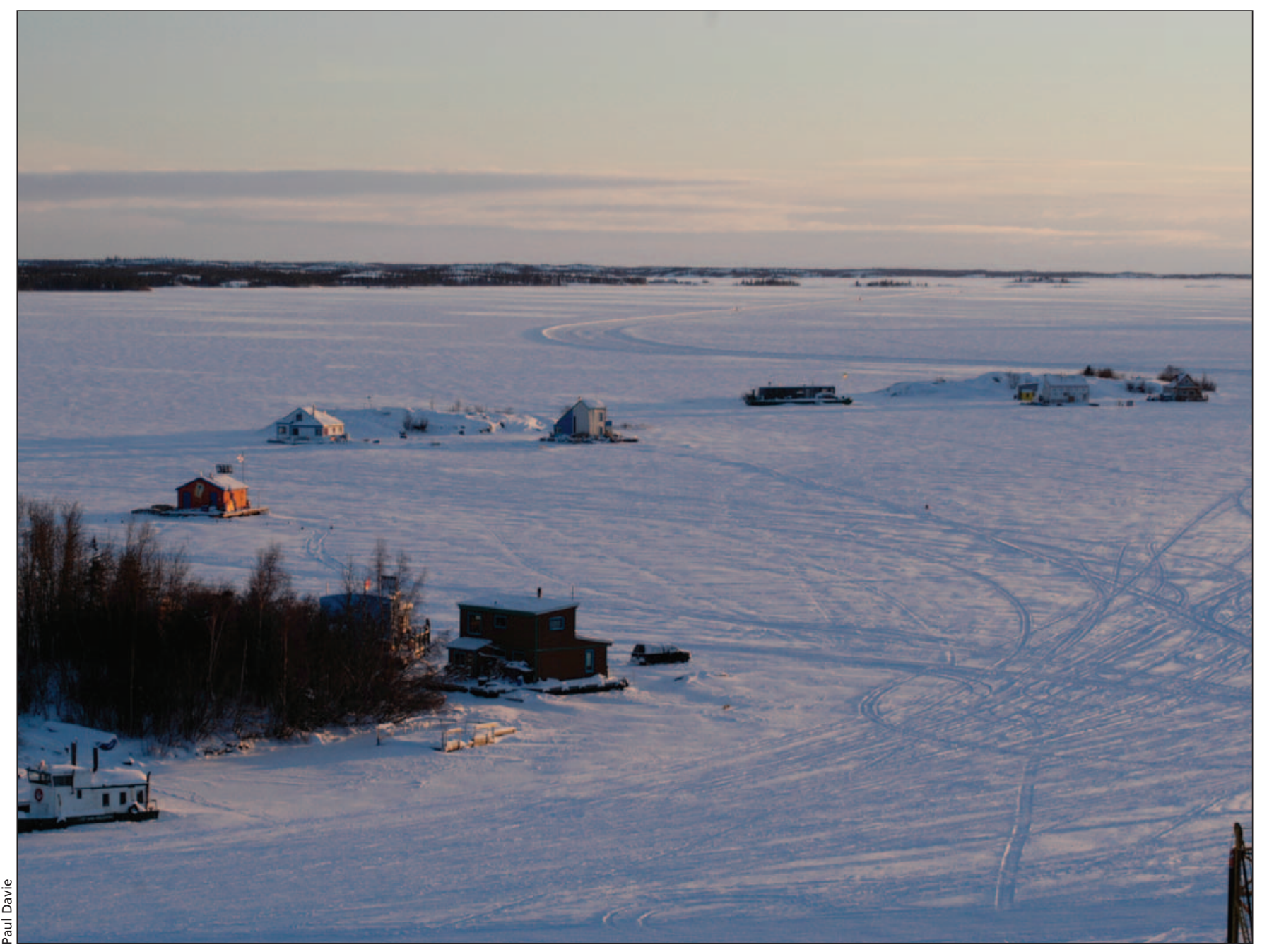


A middle-aged, cheerful fellow walked in just after me, carrying a large pot. "Beef barley," he told the patient's wife. "There's space in the fridge," she replied. He deposited the soup and left with a nod and a kind smile.

Between mouthfuls of waffles, I made some suggestions for medications and phoned the pharmacist. I spoke with the patient, who awoke from a snooze on the couch to smile warmly at his wife and submit to a brief examination.

I didn't need to know much; he had no pain, was scared, but trusting, wanted to stay home until he died and felt better with tiny doses of morphine and the occasional sleeping pill. I would come back on the weekend for another visit.

Before the next visit, I was called again - this time to declare the patient deceased and fill out the relevant paperwork.

The house was sad, but peaceful, and his wife still wore her dignity and tenderness - perfectly paired with overalls and a t-shirt. A neighbour sat in the front yard with a phone, working her way through a list of names and the coffee pot was rumbling again.

As I left, I reflected on this little town, where isolation breeds a kind of

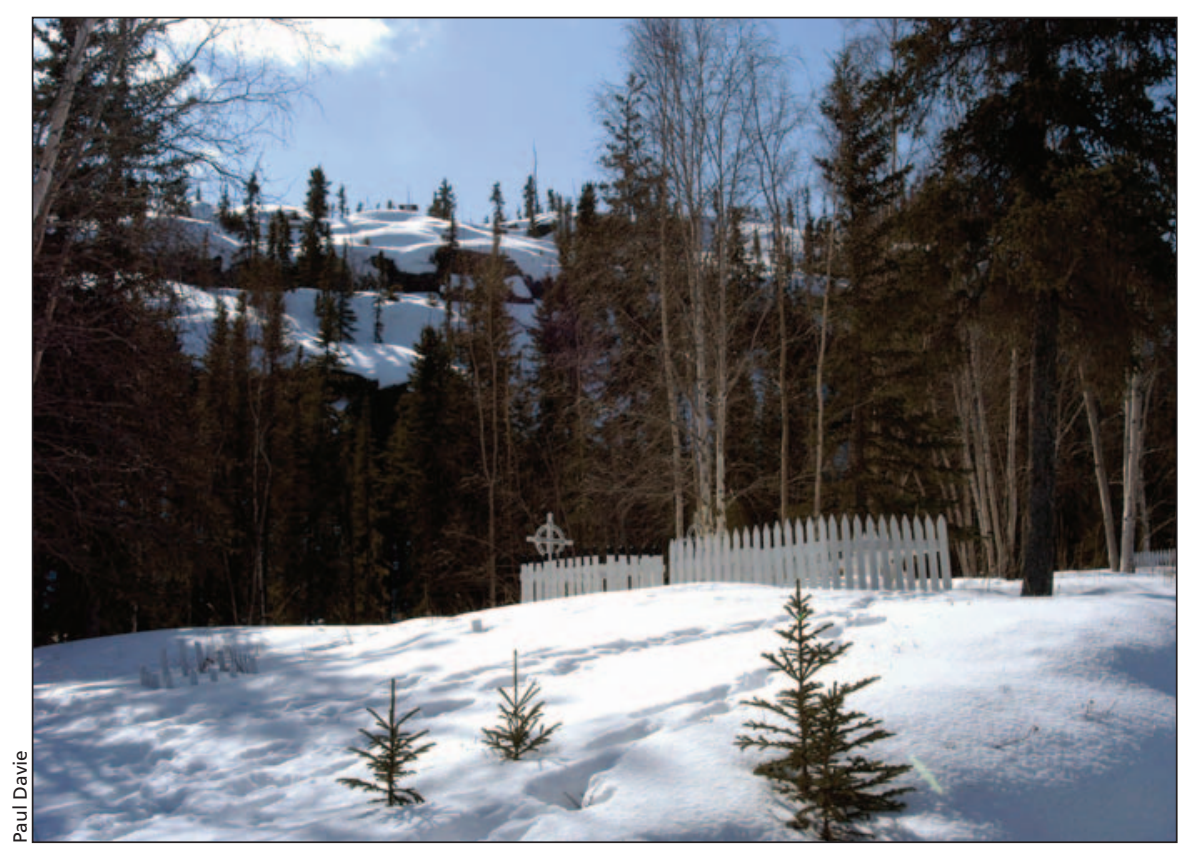

practical connection between neighbours and among health care workers. No one lives more than 15 minutes away and words are not wasted when there is soup to deliver or a prescription to pick up. Many of my patients list neighbours as their "next of kin" on hospital records. And as for the Home Care nurses - well, they know where I live, and they'll deliver an internist to your kitchen table if they think she can be of assistance.

\section{Amy Hendricks MDCM \\ Internal medicine \\ Yellowknife, NWT}

This article was previously published July 3, 2008, on Dr. Hendricks' CMAJ blog (http://cmajblog.blogspot.com/).

\section{Final exam}

I pronounced my first patient dead today, a patient whom I had never met. I was on call for our hospitalist team and received a page telling me that she had passed away in her sleep. I vaguely remembered her story from rounds - a very elderly woman who had suffered a massive stroke a month ago and never regained full consciousness - but in my first 3 days on service our team had not gathered at her bedside. Her death was expected, but not imminent. My - sign-out list said do not resuscitate: no chest compressions, no intubation, no intensive care admissions. Her family had told us of her wish to pass away without the fanfare of a code.

In medical school we were not given the specifics of how to pro- nounce a patient dead. Perhaps it was false optimism - our patients were not going to die - but more likely 4 years were not sufficient to tackle the objectives for living patients, much less the deceased. Walking down the

\section{At that moment I realized, my role was a function of formality.}

hallway from my call room, I wondered what I should do when I arrived at the bedside. I remembered the neuro exam of a comatose patient and thought of the procedures to assess brain function - but the coma exam assumes the patient is still alive. Should I walk faster? Run? I length- ened my stride, but was thankful the hospital was built wide instead of tall.

When I got to the floor, the patient's nurse, Marisol, wearing her 20-year golden RN pin, was waiting for me. These were the letters I looked for

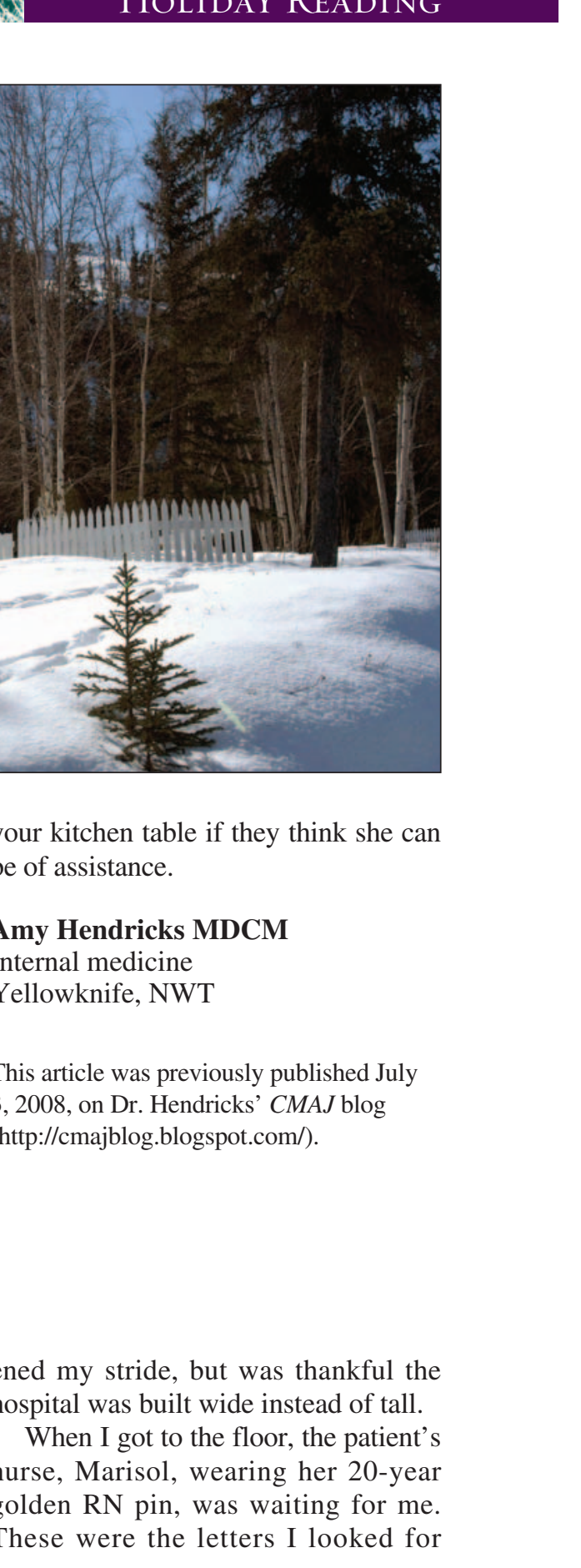

